\title{
Challenges and Solutions to Higher Education Institutions in Africa
}

\author{
Tiffany A. Drape ${ }^{1 *}$, Rick Rudd ${ }^{1}$, Megan Lopez $^{1} \&$ Donna Radford ${ }^{1}$ \\ ${ }^{1}$ Department of Agricultural, Leadership, and Community Education, Virginia Tech, 216 \\ Litton Reaves Hall, Blacksburg, Virginia, USA \\ *Corresponding author: Department of Agricultural, Leadership, and Community Education, \\ Virginia Tech, 216 Litton Reaves Hall, Blacksburg, Virginia, USA. E-mail: tdrape@vt.edu
}

Received: December 17, 2015 Accepted: January 13, 2016 Published: March 1, 2016

doi:10.5296/ije.v8i1.8742ＵRL: http://dx.doi.org/10.5296/ije.v8i1.8742

\begin{abstract}
The purpose of this study was to explore ways that higher education institutes (HEI's) that offered agriculture education and training (AET) in their curriculum could change the behavior to improve the quality of education offered to students. Faculty at a regional conference in Africa participated in a daylong focus group workshop aimed at addressing these needs and offering solutions that could be implemented immediately. Using the theory of planned behavior as a guide, participants discussed the challenges and solutions they saw at their institutions and the amount of time it would take to implement changes. A qualitative analysis was conducted using a codebook to analyze various pieces of data that included video clips and artifacts created by the participants at the workshop. Results from the analysis were split in two main themes, challenges or solutions. The main challenges included access to higher education and lack of preparation at the primary and secondary level of school. The main solutions proposed were to restructure the leadership and offer more training to faculty through mentoring programs. These results can guide higher education initiatives for agriculture education and training as well as other discipline areas in higher education.
\end{abstract}

Keywords: higher education, agriculture education, training, Africa 


\section{Introduction}

Higher education is one factor that can contribute to economic growth and development in the competitiveness of youth in an increasingly global society. For Sub-Saharan Africa (SSA), higher education plays a critical role in promoting technological advancement (or catch-up) and improving a country's ability to capitalize economically (Materu, 2007). With a population of 740 million people and 200 public universities, SSA has the lowest higher education enrollment ratio in the world at five percent. Most of the educational resources pointed towards SSA go into the primary and secondary education of students. In 1985, the World Bank was spending 17 percent of its education funding on higher education. However, in 1989 that number dropped to seven percent (Bloom, Canning, \& Chan, 2006). The allocation of funds to primary and secondary schooling increases the enrollment of students but does not conquer the problem of completion and interest in higher education to help drive growth and development to add to the economic health of SSA (Lewin, 2009).

Higher education institutions are challenged to adapt the program structures, curricula, teaching, and learning methods to account for a new necessary range of aptitudes. These aptitudes include flexibility, communication, and motivation (Materu, 2007). The main issue surrounding higher education in SSA is the poor quality of higher education institutions. The quality of the education is affected by the lack of governmental infrastructure and funding. In SSA, the corruption found in many of the governments adds to the limited funding of higher education and agriculture. Governments in SSA spend only two percent of their total budget on agriculture, even though 60 percent of inhabitants work in agriculture, where training and education can be beneficial (Fan \& Rao, 2003). The role of agriculture in economic development is beginning to come to the forefront with developing research. Agriculture is shown to play a unique role in reducing poverty and serve as an important engine for growth in developing countries due to the sheer numbers of people engaged in it through extension services and programs (Byerlee, de Janvry, \& Sadoulet 2009).

Extension services, or agricultural advisory services, refer to the range of information, advice, training, and knowledge related to agriculture or livestock production, processing, and marketing provided by most governments and non-governmental organizations (NGO's) (Meinzen-Dick, Quisumbing, Behrman, Biermayr-Jenzano, Wilde, Noordeloos, \& Beintema, 2011). Extension services can also be provided by any source that attempts to increase farmers' ability to improve not only their productivity, but also their income (Anderson, 2007). The delivery of extension services comes in many ways: individual visits, group visits, organized meetings, and use of information and communication technologies (ICTs). The teaching usually comes through the use of demonstration plots, model farms, or farmer field schools (Taye, 2013). Extension has been rapidly changing in recent years because of the advancement in ICTs and the increasing access SSA has to ICTs. This allows for mixed methods agriculture extension that includes ICTs, classroom teaching, and hands-on activities with visits from professionals (Meinzen-Dick, Quisumbing, Behrman, Biermayr-Jenzano, Wilde, Noordeloos, \& Beintema, 2011).

Progress in higher education will increase the work efficiency and social opportunities for 
students (Hall \& Jones, 1999). With the increase in commitment of students to their education, work ethic increases because of the ownership students begin to take of their future. There has also been progress in sources of inequality in SSA that will help to increase the interest of all students in higher education (Lewin, 2009). For developing countries, there is a need for more evidence on the impact of education on earnings, infrastructure, and families. This research needs to be used to create extension programs that promote the investment into and reform of financing hierarchies (Psacharopoulos \& Patrinos, 2004). This paper will investigate the background of higher education as well as the opportunities for higher education in SSA. The goal is to provide an action plan for higher education institutions (HEIs) in African countries using the constructs of the theory of planned behavior. By providing agriculture education and training in HEIs, SSA will be able to put into place an infrastructure and an ability to move toward sustainability.

\subsection{Background}

Higher Education Institutions (HEIs) including agriculture-training institutions are becoming integrated into Africa, however, that hasn't always been the case. From 1991 to 2006, the population of students attending HEIs tripled from 2.7 million to 9.3 million (Jegede, 2012). One-way most African countries are accommodating for the mass amount of student overflow is by opening private institutions. Africa now has about 800 universities and about 1,500 HEIs, a marked increase from the seven private institutions in 1960 (Jegede, 2012).

Private institutions are charged with investigating the food insecurities of specific regions to develop appropriate research to address the regional agriculture problems (Viciani, Stamoulis, \& Zezza, 2001). In order to make these changes, many organizations and associations have been put in place to ensure the growth and development of African HEIs related to agriculture education and training (AET). The "Big Eight" was formed in 2008, investing over 50 million dollars in agriculture research and development. Nigeria, Kenya, Ghana, Uganda, Tanzania, and Ethiopia are responsible for approximately 70 percent of the agriculture research and development (Beintema \& Stads, 2011). It is believed that investment in sustainable agriculture will enable people to be more educated, gain access to adequate nutrition, and create a competitive job market beneficial to each country. This is important when considering the role of higher education regarding agriculture and when examining the necessary programs and research within HEIs (Beintema \& Stads, 2011).

One organization involved in the oversight of African universities is the Association of African Universities (AAU). This organization is responsible for putting a series of objectives for each university to accomplish in place. In May 2009, AAU released the "Abuja Declaration" outlining the need for sustainable education within Africa and with the intention of producing information to provide to current education leaders and future leaders (Lozano, 2013). The focus is to ensure environmental sustainability specifically through building infrastructure, producing research, education, and creating policy changes (AAU, 2009). This declaration provides an outline to what the AAU envisions African universities might look like in the future. Understanding the direction of where organizations like AAU want to head is vital to providing educational services like AET. 
The idea of providing sustainable education practices is not new and has been discussed worldwide. The Turin declaration outlined the need to have global engagement and agriculture extension on the matter of sustainability to advocate for awareness, restructure research and education practices to include a holistic approach with the use of new technology, and help provide policy-makers with the best research and education (Lozano, 2013). These global initiatives will help organizations like the AAU with the support needed to be successful.

Despite differences in modalities and success across countries, extension refers to the conscious use of communicating information to help people form sound opinions and make good decisions (Taye, 2013). The adoption of technologies and better practices is the core of extension interventions. Certain farmers in extension need to pass in a specific process before achieving their ultimate goal of improving productivity. The process includes awareness, knowledge, adoption of technology or practice, and change in farmers' productivity (Taye, 2013). Because of this, various extension methods are used, such as extension contacts, meetings, mass media, demonstrations, etc. In addition to these, there are informal networks and communications where technologies, knowledge, and practices are spread to other farmers.

The World Bank has supported small-scale extension initiatives in Africa since 1970, when the World Bank started financing integrated rural development projects. Following the change in its emphasis from integrated rural development projects to the development of national institutions in the early 1980s, the World Bank began to support reorganization of national agricultural extension systems in Africa (Feder, Willett, \& Zijp, 1999).

\subsection{Opportunities and Growth}

The growth of private and quasi-private higher education institutions is becoming more and more common in SSA. The quasi-private institutions are good at collecting and utilizing resources for themselves, however, a major percentage of their resources come from the state (Varghese, 2006). Privatization of public institutions has taken on different forms to be implemented in certain segments of the university sector. This includes the withdrawal of subsidies and cost sharing with students (Varghese, 2006). If students begin to contribute to their own education financially, the reduction in demand for higher education funding could result in a greater proportion of resources being used in primary and secondary education (Hinchliffe, 1985). The increase in the private contributions would be the supply of the funding towards primary and secondary schooling (Psacharopoulos \& Patrinos, 2004).

A World Bank study of higher education and economic development in SSA stated, "[Donor institutions] have neglected tertiary education as an added means to improve economic growth and mitigate poverty... Because of a belief that primary and secondary schooling are more important than tertiary education for poverty reduction, the international development community has encouraged African governments' relative neglect of higher education" (Bloom, Canning, \& Chan, 2006, pg. 1,6). With a shift to privatization and cost-sharing tuition techniques, enrollment and completion rates will rise. The research opportunities and findings that would then come from SSA would increase and bring more positive attention to academia in SSA and would also bring more jobs (Bloom, Canning, \& Chan, 2006). Donors and government funding attempt to offset the cost of higher education but this has proven to be a 
negative motivator for students. The students become complacent and unmotivated to take ownership of their education (Hinchliffe, 1985). Asking students to fund part or all of their education could increase their level of commitment to study, this would reduce dropout rates (Hinchliffe, 1985).

Investment in extension services is an important tool for improving agricultural productivity and increasing farmers' incomes (Anderson, 2007). Therefore, many donors have been supporting efforts of developing countries in providing extension services. Most SSA countries have been providing agricultural extension services for the last several decades even if the modalities have shown changes over the years. This is another opportunity for SSA to keep up extension services with farmers and HEIs (Taye, 2013).

Growth in higher education in SSA should look to expand opportunities available for potential students to include relevant vocational occupations in their region. These opportunities include expanding education to become interdisciplinary while improving the current learning environments to help motivate students. Higher education should consider helping universities to focus on the specific problems of their region and increasing the efficacy and motivation in students to take responsibility for their education by being more financially liable. Finally, universities may want to provide more research opportunities for faculty and students to partner in together to increase graduation rates.

Education should be interdisciplinary to highlight the important connections between the interests of the students and the needs of their particular region (Kroma, 2003). The current structure of education is solely lecture based, however, the evolution of higher education should push towards problem solving and social interaction as pedagogies (Kroma, 2003). Better learning environments foster better work ethics and an overall higher motivation for students to complete their education. A one-year increase in higher education completion would raise the long-run steady-state level of African GDP per capita ten times (Bloom, Canning, \& Chan, 2006).

\subsection{Challenges}

Africa has been facing and addressing many problems regarding universities, population growth, and infrastructure. All three of these challenges are contributing to some parts of Africa being unable to provide proper primary education, a job market, and health services to the people in and out of remote areas (Goliber, 1985). With the steadily increasing population, the number of students attempting to enter the university is larger; however, the universities are not able to admit all students, causing a surge in the opening of private universities (Jegede, 2012). The number of students wanting to participate in higher education without the proper background and training is only one aspect of the problems. Students who do enter HEIs majoring in agriculture related areas may not have any background knowledge in agriculture from their secondary school preparation, making completing a program more difficult and increasing the learning curve in a limited amount of time (Edziwa \& Ncube, 2013). It is estimated that 70 percent of the labor force in SSA work in agriculture in rural areas of the country and live on less than one US dollar per day (Aker, 2010; Byerlee, de Janvry, \& Sadoulet 2009). 
Creating programs and research institutions that can tackle the food security problem can be one of the most difficult tasks facing extension agents depending on the location of the institution. Certain countries and existing institutions have policies that are nearly impossible to circumvent when developing and implementing new research and outreach programs (Feder, Willett, \& Zijp, 1999). Government failure to allocate necessary funds to run extension systems is one key indication of such lack of commitment or existing policies that are not allowing commitment (Feder, Willett, \& Zijp, 1999). Therefore, the effectiveness of extension programs relies heavily on relaxing barriers to the successful development of the agricultural sector as a whole (Purcell and Anderson, 1997).

Despite program creation and implementation in SSA, it is difficult to measure their success because the outputs are nearly impossible to quantify from outside of the community in a short period of time (Davis, 2008). Evaluating a programs' impact involves being able to measure the relationship between the program activities and change over time on the awareness, knowledge, and adoption of the proposed practice. Knowledge, awareness, and adoption of particular technologies or practices can be slow to change or be quantified for evaluation purposes. Purcell and Anderson (1997) were able to observe serious data constraints and were unable to include all the contributing variables affecting production outcomes. This is because numerous factors contribute to a specific production response and to existing farmers' decisions about the use of available resources (Feder, Willett, \& Zijp, 1999).

Other challenges that the universities face are funding, lack of resources, and lack of research within private universities (Jegede, 2012). When programs are created with the intention of helping students and countries learn and work together through research and development, a new set of problems arise. Sustaining programs created to bring about change is one of the most challenging obstacles SSA would face after implementation (McCole, Culbertson, Suvedi, \& McNamara, 2014). The lack of sustainability is caused by poor conditions at the public universities where there is a high turnover amongst faculty so if research is even being conducted then it becomes lost in the transition (Blackie, Blackie, Lele, \& Beintema, 2010). Creating an environment that promotes sustainability and perseverance is difficult to complete successfully. Time and resource investment into agriculture education is one of the many important ventures that is known to create systems of sustainability (McCole, Culbertson, Suvedi, \& McNamara, 2014).

\section{Theoretical framework}

The theory of planned behavior can be broken down into four main parts: the action performed, the target at which the action is directed, the context in which it is performed, and the time at which it's performed. Each part is fluid and can be altered based on the needs of the intended audience (Fishbein \& Ajzen, 2010). Performance and motivation is commonly determined by the student or employee's behaviors and by factors in the education or work environment that help or hinder productivity (Ajzen, 2011). Part of planned behavior is motivation, which is linked to self-regulated learning and is an important aspect to consider when integrating agriculture education and technology into developing countries. Having a student or employee 
who is a self-regulated learner allows for effective learning, self-efficacy, self-motivation, ability to plan, and seek help when necessary and be able to reflect on past learning experiences to look to the future (Bandura, 1977; Ormrod, 2012).

The aspects of self-regulated learning need to be integrated into curriculum and learning practices in SSA to insure further development of learning. A key part of self-regulated learning is starting with the co-regulated learning, which allows a mentorship between one with higher abilities in a certain subject like agriculture to help one with lower abilities or knowledge in the subject area to improve and eventually move toward self-regulated learning (Ormrod, 2012). Creating an environment of self-regulated learners can increase productivity among the audience to perpetuate the cycle when they return to their universities to encourage students and other faculty to become self-regulated learners.

In order to improve the planned behavior of SSA students, their expectation of increased work ethic needs to improve. The assertion of this theory is not static in nature, it needs to take into account the effect of behavior on cognition and future behavior (Ajzen, 2014). These effects can be represented by feedback loops that are described by the following statement:

"When a behavior is carried out, it can result in unanticipated positive or negative consequences, it can elicit favorable or unfavorable reactions from others, and it can reveal unanticipated difficulties or facilitating factors. This feedback is likely to change the person's behavioral, normative, and control beliefs and thus affect future intentions and actions" (Fishbein \& Ajzen, 2010, p. 218).

When this theory is applied to effort in education or in a career, the beliefs in question are mostly beliefs about the likely consequences of exerting effort in their field. A relatively small amount of beliefs will influence a person's attitude towards their behavior (Ajzen, 2011). Attitude needs to be shifted from education and job performance to education and job satisfaction. When the expectation of students or employees changes, the outcome and production will improve (Fishbein \& Ajzen, 2010).

Planned behavior also depends on commitment and intention (Ajzen, Czasch, \& Flood, 2009). Students in higher education in SSA can change the outcome of their education by slowly changing their commitment level, intentions, and attitudes in a positive way. The feedback loop is affected greatly once the small changes take place; it causes a positive ripple effect in behavior (Fishbein \& Azjen, 2010).

Intentions are indicators of a person's readiness to perform a behavior and are directly linked to the efficacy that the behavior will result in a favorable outcome based on the persons estimate. The amount of effort and motivation directly relates to this. Data from the conference suggests that participants planned small, deliberate changes to the behavior that would also help contribute to the larger goal of a conceptual shift in the higher education institution. 


\section{Purpose}

The purpose of this study was to explore the needs of higher education professionals at a regional conference during a one-day workshop geared toward immediate and long-term improvement. Two research questions guided this inquiry:

1. Which issues were the most important to higher education officials in sustaining and growing their institutions?

2. What solutions could be implemented to begin the process of improving higher education in Africa?

\section{Methodology}

To promote higher education development, we present focus group data from an international conference in Africa that has been transcribed and coded to highlight the main current issues and possible solutions of higher education success in SSA and a compilation of literature that demonstrate problems and suggest solutions especially in regards to agriculture education. A focus group study is a carefully planned series of discussions designed to obtain perceptions on a defined area of interests (Krueger \& Casey, 2009). Focus groups are meant to be nonthreatening and participants are encouraged to share their points of view without pressuring participants. Facilitators conducted multiple focus groups to detect patterns and trends and conduct an analysis to provide clues and insights that are uncovered as a result (Krueger \& Casey, 2009).

The international conference is a consortium of 42 universities in 19 countries of Eastern, Central and Southern Africa (ECSA). The group's mission is to strengthen the capacities of universities to foster innovations responsive to demands of smallholder farmers through the training of high quality researchers, the output of impact-oriented research, and the maintenance of collaborative working relations among researchers, farmers, national agricultural research institutions, and governments (Who We Are, 2010).

Data was collected from a conference workshop titled, "Challenges for Higher Education in Africa" as part of the larger conference. Participants from various universities and countries participated in the workshop, discussing best practices, and creating artifacts for transcription and coding using the USAID framework to guide the conversation. Each focus group had approximately five participants who were given several prompts and topics to discuss while recording their thoughts on paper. Facilitators posed questions and gave ample time for each group to discuss the topic. The facilitators worked with each group individually to engage in their conversation, ask follow up questions, and get clarification on anything the group was discussing. Data was transcribed and analyzed using an open coding scheme and then a focused coding scheme to put open codes into specific subsets.

\subsection{Participants}

The participants consisted of various faculty and university employees from up to 45 different countries. They came from a variety of backgrounds including ministers, chairpersons, 
university principals and deans, vice chancellors, faculty members, and graduate students. Twenty people participated in the group discussion based off their interest in the topic (RUFORM, 2014).

\subsection{Data Collection Plan}

Data was collected from two sources: artifact generation and video. Artifact collection took place throughout the day, using tear sheets from group activities and action plans that participants generated as a result of participating in the workshop. Artifacts collected were photographed and archived for travel back to the researchers' university. Videos were collected throughout the day and while the artifacts were being generated. The data was collected and archived for travel using a tablet that was password protected by a single researcher.

\subsection{Data Analysis}

Artifacts were transcribed and coded using an open coding scheme. Development of the codebook emphasized the action-oriented nature of language (Roth, 2008) in which participants discussed the challenges and rewards to changing their behavior in higher education. Analysis of the artifacts and video data was based on an attempt to understand the issues facing higher education and solutions that could be implemented to improve it. The coding was focused, using coding scheme based on the USAID framework (USAID, 2014). The video data collected from the group interactions was transcribed, coded, and analyzed for challenges and proposed solutions from participants. Using constructs from the studies presented in the literature review and the seven items in the USAID framework challenges to higher education, a codebook was created to categorize their perception of challenges and solutions within higher education in SSA (USAID, 2014). Two additional codes were added as a result of the initial coding process when they appeared multiple times as a theme. Videos and other artifacts were transcribed and researchers examined the data line by line to code the transcriptions for all of the sub codes mentioned below.

- Access to Education

- Broad Government Issues

- Institutional Leadership and Management

- Financing Higher Education

- Limited Research Investment

- Quality and Relevance of Learning

- Information and Communication Technologies

- Location of Institutions

- Mentorship

- Family Structure

- Primary and Secondary School Preparation

Two researchers coded the data for the purpose of inter-rater reliability (Charmaz, 2006). By comparing data to data, focused codes were created to help the researchers begin grouping similar codes. This allowed finding themes throughout the analysis and determines specific themes found by all researchers. The challenges outlined by USAID posed as the problem and 
solution sub-codes to see how often a specific challenge was pointed or if tackling that challenge could be a possible solution to many problems. This helped the researchers see which challenges are important problems to address and which ones seem to be the most important in fixing the higher education system in SSA. When a challenge was written or discussed as a problem, a tally was giving to that challenge in the problem column. Inversely, if a challenge was written or discussed as a solution, a tally was given to that challenge in the solution column.

After open coding was complete, focused coding occurred. The resulting codes were more direct and began to explain larger segments of the data. Focused coding helped determine the adequacy of the in vivo codes (Charmaz, 2006). By comparing data to data, focused codes were created to help the researcher begin grouping like codes and refining them into larger groups of categories. The final step in the coding process was axial coding. Axial coding helped the researcher bring all of the data together and determine themes based on the research questions (Corbin \& Strauss, 2008).

\section{Findings}

\subsection{Challenges}

From the tear sheets and discussions, program participants outlined challenges. Based on those artifacts, the main challenges proposed by the workshop participants revolved around student access to higher education with the lack of preparation in primary and secondary school. Several constraints limited prospective students' access to higher education including language barriers, access to basic services, and educational preparation. The lack of reliable power and electricity in rural areas limited any kind of technology or electronic communication between potential students, their families, and the universities. Common language was also not consistent in each region and could limit the number of HEI's a student can even attend for their major of choice.

"We also discussed that the structure should be flexible enough to respond to changing environments. One of the problems we pointed out in our first presentation was the process. We decide that there should be a well-monitored mechanism for quality assurance, that student evaluation and assessment should be done at the end of the course or semester and that young faculty members can be mentored by senior faculty members based on student assessment."

Finally, students trying to prepare for admission to a HEI are often ill prepared due to an inconsistent curriculum during their primary and secondary education programs. This negatively affected their ability to apply and be admitted. Primary and secondary education programs did not adequately communicate all of the options available to students upon completion and there was little guidance or mentoring of students to prepare them for university admissions. One participant suggested a bridging program to help with enrollment,

"There are also bridging programs. Before you can get into some schools in Africa they have a cut-off mark, maybe $60 \%$ of an exam, and if the students are not able to 
make up that percentage they are denied admission. So we have, we are suggesting a bridging program which would take up those students that fail."

Two similar issues involved limited research investment that is detrimental to the quality of HEIs. Research is a pivotal part of HEIs because of the innovation that drives curriculum and the application of theory that undergraduate and graduate students need to experience. Without this experience, participants described students that were unprepared for the workforce and unsupported by their one-sided education. Lack of support for the graduate students in their research interests that could have propelled innovation for HEIs was also outlined as a concern. One participant said, "without innovative research and with students ending their programs unprepared to sound methodology to their research, the quality of the HEI is depleted quickly." Conference participants attributed the poor quality of HEIs to the lack of monitoring of current leadership and programs and also the lack of flexibility in HEI infrastructure.

\subsection{Solutions}

The most proposed solution that could begin changing immediately addressed the lack of communication between HEIs and prospective students, primary and secondary education institutions, and industries. A participant reflected, "without communication, prospective students don't know the opportunities that are available to them... industry and government isn't receiving information about research." Communicating and being more transparent could help raise awareness of the opportunities present at HEIs could make family and communities more informed and make higher education an option. This would start the higher education conversations in the homes earlier and more frequently. Showcasing a HEI's opportunities and research will help to rebrand HEIs as a whole by reforming public opinion. Communication encapsulated the internal communication between departments, administration, and HEI and government infrastructure. With these lines open, government officials would be more aware of their constituents' interests and needs and would reduce overlapping duties throughout the administration. This would increase the efficiency of the HEI and allot time for the mentorship mentioned in the previous paragraph. If the communication was increased and channels of exchange were opened up between HEIs and students, higher education in SSA has the potential to move forward.

The other recommendations by workshop participants involved restructuring the hierarchy of the leadership of HEIs to include better training, financing, and research for faculty and students. One participant stated,

"There is need for mentorship and coaching where junior staff are paired with senior staff in order to help them stream-line what they are doing, what they see themselves doing, what they want to achieve, how do they get there, all that."

Programs that include mentorship will be more successful because of the open lines of communication between younger faculty and older faculty and also between faculty and students, "mentorship needs to become part of the solution for both faculty and students." Training could come in the form of mentorship where older faculty and younger faculty come together to create research opportunities and teach together. This will transfer to the student 
experience when they join the faculty to research and learn. Financing is a challenge for students and HEIs as a whole. Restructuring financial programs and fostering a higher investment in scholarship programs for students will change the way prospective students look at higher education. Financial restructuring is notorious for being difficult in areas like SSA because of the political corruption present. A side effect of higher quality education offered by HEIs would be an improvement of the government infrastructure that affects the development of HEIs.

\section{Recommendations/Conclusions}

Based on the data collected and examination of the literature, the main challenges lie in communication and technology, access, infrastructure, and research. The main aim was to provide simple new constructs to improve the current situation and contribute to the overarching goal of HEIs using the theory of planned behavior. Through analysis of the data, the researchers found commonalities amongst the desires outlined by HEIs in Sub-Saharan Africa. With this in mind, the researchers have come up with several suggestions.

In order to change behavior, opportunities must be available to help faculty begin the process (Fishbein \& Ajzen, 2010). Integrating technological advances such as mobile phones into rural areas will provide a source of communication for both potential students and faculty to increase access and begin to break down perceived barriers to applying or seeking higher education. Mobile phones are extending into agriculture education and extension in countries like Kenya, Uganda, and India can text or call hotlines to ask for technical advice on growing their crops (Aker \& Mbiti, 2010).

Another way to increase exposure to people in rural areas is to expand the regional center or a similar model that will work for that region. Faculty who travel to the regional center to teach classes or workshops with extension services will be able to gauge the local populations, their needs, and how they can tailor their offerings for that region. By spending more time in a particular region, it may also offer exposure to the public school and other educational systems that teach students who could potentially be interested in attending a HEI after completion. The regional center and schools could partner to undertake agricultural research problems, engaging with students to help with the process and attract them through active participation. Extension services and faculty could work with the administrators at the schools to help ensure students are meeting educational requirements and faculty could see what students are learning during their primary and secondary years in school to help bridge any gaps. Increasing access and equity to higher education can be done in multiple ways and starting by forming a relationship and providing a regular presence in rural areas with stakeholder groups can help ease some of the barriers.

At the university level, faculty and staff can benefit from mentoring at a formal or informal level. Creating mentoring relationships among senior faculty and new faculty can help both groups in different ways. New faculty can benefit from the experience a mentor brings, learning about the university system, aiding with research, and dissemination. Mentor faculty can benefit by working with a younger peer who will bring fresh ideas to the university and 
both can benefit from the collaborative environment that a mentoring relationship can help foster.

Universities should consider partnering with agriculturally based companies and business to help with the advancement of agriculture in SSA for input on curriculum, internship and employment sites for graduates, potential ethical research partnerships, and other opportunities that can be mutually beneficial to both parties. This could help create an infrastructure where agriculture can be researched extensively paired with education to give proper training to help improve food sustainability. This may also offer opportunities to help students fund their education through scholarships, fellowships, and other types of financial opportunities to help offset the cost of attending a HEI.

The main goal is to provide both the HEIs and the people of SSA with the resources necessary to succeed and move forward in terms of providing quality education and conducting agricultural research that can be disseminated on a global scale. Having a strong foundation in agriculture will lead to stronger infrastructure and sustainability within these regions. Helping them reach their overarching goals will help increase their self-efficacy and in turn help create favorable outcomes. With the current recommendations, HEIs in SSA will be able to be prepared and ready to carry out these outcomes. Each recommendation employs the basics of the theoretical framework provided such as self-regulated learning, commitment, and intention with a focus on education.

Higher education in SSA has a significant amount of work ahead to reach their overall goals. Using the theory of planned behavior as a guide and aligning incremental and measurable changes in higher education, faculty may be more motivated to continue working to improve their institutions (Ajzen \& Madden, 1986). By openly discussing the challenges and solutions, commonalities were found and proposed solutions could be worked through with a group, creating common goals and offering networking opportunities for the faculty involved. Working in a group could also bolster the intentions of the participants, increasing the likelihood they will engage in changing their behavior (Ajzen, 1991). Small changes over time will begin to make an impact with the faculty, the students, and the institution.

\section{Acknowledgement}

This work was funded by USAID and InnovATE under USAID/BF /ARP-Funded Project Award Number: AID-OAA-L-12-00002

\section{References}

Ajzen, I. (1991). The theory of planned behavior. Organizational behavior and human decision processes, 50(2), 179-211. http://dx.doi.org/10.1016/0749-5978(91)90020-t

Ajzen, I. (2011). Job satisfaction, effort, and performance: a reasoned action perspective. Contemporary Economics, 5(4), 32-43. http://dx.doi.org/10.5709/ce.1897-9254.26 
Ajzen, I. (2014). The theory of planned behavior is alive and well, and not ready to retire: a commentary on Sniehotta, Presseau, and Araújo-Soares. Health Psychology Review, (ahead of print), 1-7. http://dx.doi.org/10.1080/17437199.2014.883474

Ajzen, I., \& Madden, T. J. (1986). Prediction of goal-directed behavior: Attitudes, intentions, and perceived behavioral control. Journal of experimental social psychology, 22(5), 453-474. http://dx.doi.org/10.1016/0022-1031(86)90045-4

Ajzen, I., Czasch, C., \& Flood, M. G. (2009). From intentions to behavior: Implementation intention, commitment, and conscientiousness. Journal of Applied Social Psychology, 39(6), 1356-1372. http://dx.doi.org/10.1111/j.1559-1816.2009.00485.x

Aker, J. (2010). Dial “A” for agriculture: using information and communication technologies for agricultural extension in developing countries. In Conference Agriculture for Development-Revisited, University of California at Berkeley, October (pp. 1-2).

Aker, J. C., \& Mbiti, I.M. (2010). Mobile phones and economic development in Africa. Journal of Economic Perspectives, 24(3), 207-232. http://dx.doi.org/10.1257/jep.24.3.207

Anderson, J.R. (2007). 'Agricultural advisory services.' Background Paper for World Development Report 2008, Agriculture for Development, World Bank, Washington, DC. http://dx.doi.org/10.1596/978-0-8213-7297-5

Association of African Universities. (2009). Abuja Declaration on Sustainable Development in Africa: The Role of Higher Education. Proceedings of the 12th General Conference of $A A U$, Nigeria.

Bandura, A. (1977). Self-efficacy: Toward a unifying theory of behavioral change. Psychological Review, 84(2), 191-215. http://dx.doi.org/10.1037/0033-295x.84.2.191

Beintema, N. M., \& Stads, G. J. (2011). African agricultural R\&D in the new millennium: Progress for some, challenges for many (No. 24). International Food Policy Research Institute (IFPRI). http://dx.doi.org/10.2499/9780896295438

Blackie, M., Blackie, R., Lele, U., \& Beintema, N. (2010, November). Capacity development and investment in agricultural $\mathrm{R} \& \mathrm{D}$ in Africa. Lead background paper ministerial conference on higher education in agriculture in Africa. Speke Resort Hotel, Munyonyo, Kampala, Uganda.

Bloom, D. E., Canning, D., \& Chan, K. (2006). Higher education and economic development in Africa (No. 102). Washington, DC: World Bank.

Byerlee, D., De Janvry, A., \& Sadoulet, E. (2009). Agriculture for development: Toward a new paradigm. Annual Review of Resource Economics, 1(1), 15-31. http://dx.doi.org/10.1146/annurev.resource.050708.144239

Charmaz, K. (2006). Constructing Grounded Theory. Thousand Oaks: Sage Publications, Inc.

Davis, K. (2008). Extension in sub-Saharan Africa: Overview and assessment of past and 
current models and future prospects. Journal of International Agricultural and Extension Education, 15(3), 15-28.

Edziwa, X., \& Ncube, A. (2013). Subject Content-efficacy and Skills Proficiency of Trainee Agriculture Teachers Holding National Certificate in Agriculture, Zimbabwe. International Journal of Education, 5(2), p15-p26. http://dx.doi.org/10.5296/ije.v5i2.3066

Feder, G., Willett, A., \& Zijp, W. (1999). Agricultural Extension: Generic Challenges and Some Ingredients for Solutions. Policy Research Working Papers. http://dx.doi.org/10.1596/1813-9450-2129

Fishbein, M., \& Ajzen, I. (2010). Predicting and changing behavior: The reasoned action approach. New York: Psychology Press.

Goliber, T. J. (1985). Sub-Saharan Africa: population pressures on development. Population Bulletin, 40(1), 1-46.

Hall, R. E., \& Jones, C. I. (1999). Why do some countries produce so much more output per worker than others? (No. w6564). National bureau of economic research.

Hinchliffe, K. (1985). Higher education in sub-Saharan Africa. Washington, DC: World Bank. Jegede, O. (2012). The status of higher education in Africa. Paper for panel discussion in the launch of Weaving Success: Voices of Change in African Higher Education-A project of the partnership for Higher Education in Africa (PHEA) held at the Institute of International Education, New York.

Kroma, M. (2003, April). Reshaping extension education curricula for 21 st century agricultural development in sub-Saharan Africa. In 19th Annual Conference of the Association of International Agricultural and Extension Education," Raleigh, NC, USA, April (pp. 8-12).

Krueger, R. A., \& Casey, M. A. (2009). Focus Groups: A Practical Guide For Applied Research. Sage.

Lewin, K.M. (2009). Access to education in sub-Saharan Africa: Patterns, problems, and possibilities. Comparative Education, 45(2), 151-174. http://dx.doi.org/10.1080/03050060902920518

Lozano, R., Lukman, R., Lozano, F. J., Huisingh, D., \& Lambrechts, W. (2013). Declarations for sustainability in higher education: becoming better leaders, through addressing the university system. Journal of Cleaner Production, 48, 10-19. http://dx.doi.org/10.1016/j.jclepro.2011.10.006

Materu, P. N. (2007). Higher Education Quality Assurance in Sub-Saharan Africa. World Bank Working Papers. http://dx.doi.org/10.1596/978-0-8213-7272-2

McCole, D., Culbertson, M. J., Suvedi, M., \& McNamara, P. E. (2014). Addressing the Challenges of Extension and Advisory Services in Uganda: The Grameen Foundation's 
Community Knowledge Worker Program. Journal of International Agricultural and Extension Education, 21(1), 6-18.

Meinzen-Dick, R., Quisumbing, A., Behrman, J., Biermayr-Jenzano, P., Wilde, V., Noordeloos, M., \& Beintema, N. (2011). Engendering agricultural research, development and extension (Vol. 176). International Food Policy Research Institute. http://dx.doi.org/10.2499/9780896291904

Ormrod, J.E. (2012). Human learning (6th ed.). Pearson Publishing Company.

Psacharopoulos, G., \& Patrinos, H. A. (2004). Returns to investment in education: a further update. Education economics, 12(2), 111-134. http://dx.doi.org/10.1080/0964529042000239140

Purcell, D., \& Anderson, J. R. (1997). Agricultural extension and research: Achievements and problems in national systems. World Bank Publications.

Roth, W. M. (2008). The nature of scientific conceptions: a discursive psychological perspective. Educational Research Review, 3(1), 30-50. http://dx.doi.org/10.1016/j.edurev.2007.10.002

Stamoulis, K.G. (Ed.). (2001). Food, agriculture, and rural development: current and emerging issues for economic analysis and policy research. Food \& Agriculture Organization.

Taye, H. (2013). Evaluating the impact of agricultural extension programs in sub-Saharan Africa: Challenges and prospects. African Evaluation Journal, 1(1), 9-pages. http://dx.doi.org/10.4102/aej.v1i1.19

USAID. (2014). African higher education: Opportunities for transformative change for sustainable development. Washington, D.C.: APLU.

Varghese, N. V. (2006). Growth and expansion of private higher education in Africa (ed.). Paris: IIEP/UNESCO.

\section{Copyright Disclaimer}

Copyright for this article is retained by the author(s), with first publication rights granted to the journal.

This is an open-access article distributed under the terms and conditions of the Creative Commons Attribution license (http://creativecommons.org/licenses/by/3.0/). 